DEBT POLICY, CORPORATE TAXES, AND DISCOUNT RATES

Mark Grinblatt

Jun Liu

Working Paper 9353 
NBER WORKING PAPER SERIES

\title{
DEBT POLICY, CORPORATE TAXES, AND DISCOUNT RATES
}

Mark Grinblatt

Jun Liu

Working Paper 9353

http://www.nber.org/papers/w9353

\author{
NATIONAL BUREAU OF ECONOMIC RESEARCH \\ 1050 Massachusetts Avenue \\ Cambridge, MA 02138 \\ November 2002
}

The authors thank the UCLA Academic Senate and the Harold Price Center for Entrepreneurial Studies for financial support and seminar participants at the University of Arizona, the University of Kentucky, and the 2002 Financial Management Association meeting for comments on earlier drafts. The views expressed herein are those of the authors and not necessarily those of the National Bureau of Economic Research.

(C) 2002 by Mark Grinblatt and Jun Liu. All rights reserved. Short sections of text, not to exceed two paragraphs, may be quoted without explicit permission provided that full credit, including (C) notice, is given to the source. 
Debt Policy, Corporate Taxes, and Discount Rates

Mark Grinblatt and Jun Liu

NBER Working Paper No. 9353

November 2002

JEL No. G0, G1

\section{$\underline{\text { ABSTRACT }}$}

This paper studies the valuation of assets with debt tax shields when debt policy is a general time-dependent function of the asset's unlevered cash flows, value, and history. In a continuous-time setting, it shows that the value of a project's debt tax shield satisfies a partial differential equation, which simplifies to an easily solved ordinary differential equation for most plausible debt policies. A large class of cases exhibits closed-form solutions for the value of a levered asset, the value of its tax shield, and the appropriate tax-adjusted cost of capital for discounting unlevered cash flows.

Mark Grinblatt Anderson Graduate School of Management UCLA 110 Westwood Plaza

Los Angeles, CA 90095-1481

and NBER

mark.grinblatt@anderson.ucla.edu
Jun Liu

Anderson Graduate School of Management UCLA 110 Westwood Plaza Los Angeles, CA 90095-1481

jliu@anderson.ucla.edu 
Perhaps the most popular application of financial theory is capital budgeting. Virtually every student of finance starts his education in the field by learning how to discount future cash flows. By the end of a first course, the student has developed the basic tools to implement a discounted cash flow analysis in a real world setting. Because the real world setting must account for the relative advantage of debt financing, arising from the debt interest tax subsidy, students of finance generally learn that such subsidies can be accounted for by discounting unlevered cash flows (also referred to as "free cash flows") at a tax-adjusted weighted average cost of capital (or $W A C C$ ). Such tax adjustments to the discount rate generate a value for levered assets that exceed the value they would have if they were not levered with debt financing. ${ }^{1}$

Despite the central importance of this topic, research on how to do a proper valuation for capital budgeting purposes is sparse and largely ancient, particularly when it comes to debt tax shields. An intrinsic difficulty associated with the valuation of debt tax shields is identifying the risk of the tax deductions arising from the stream of future debt interest expenses. The rate at which one discounts the future stream of interest-related tax shields, and hence the value of those tax shields, has eluded prior research, except for the simplest of cases.

These cases impose stringent restrictions on the cash flow process and debt policy to circumvent the complex issue of risk and valuation. Among these are the models of Modigliani and Miller (1958) and Miles and Ezzell (1985). The Modigliani and Miller debt policy is one where the debt level is constant and debt is both perpetual and default-free. This debt policy implies that one can discount the stream of future interest-based tax shields at the risk-free rate. If the tax rate is constant, as they assume, the debt tax shield's present value is necessarily proportional to the present value of the debt because the cash flow stream from debt and the tax shield are proportional to one another. Here, since the constant of proportionality is the corporate tax rate, the present value of the debt tax shield is the product of the corporate tax rate and the present value of the debt. Modigliani and Miller (1958) also use this model to develop formulas for discount rates that account for the value of the tax shield when cash flows have no tendency to grow.

The interesting case studied by Miles and Ezzell focuses on the dynamic issuance of perpetual risk-free debt. This case assumes: 1) the unlevered cash flow realization at each date follows a random walk with no drift, which is paid out upon its realization (hence there is no expected growth), 2) the unlevered cash flow stream is valued by applying a constant discount rate, and 3) the debt-to-asset ratio is constant. Under these assumptions, the cash flow from each date's tax shield is of the same risk as the one period lagged unlevered cash flow. As Grinblatt and Titman (1997, 2002) and Brealey and Meyers (2000) point out,

\footnotetext{
${ }^{1}$ Despite attempts to introduce the Adjusted Present Value method into the classroom, the Weighted Average Cost of Capital approach still vastly dominates the practitioner landscape. For example, Graham and Harvey (2001) observe that of twelve capital budgeting techniques, many of which are long out of favor with finance academics, the Adjusted Present Value method is the least-used method.
} 
in the continuous time limit of this model, the cash flow stream from future debt-related tax deductions is of the same risk as the stream of unlevered cash flows and thus can be discounted at the same rate as the unlevered cash flows. Miles and Ezzell, as well as the standard textbooks, present formulas analogous to those in Modigliani and Miller for this alternative debt policy.

It would be an extraordinary coincidence if cash flow processes and debt policies matched those of the Modigliani-Miller or Miles-Ezzell models. For this reason, a more general analysis is of great importance to the field of finance. In this paper we provide a comprehensive analysis of the value of the risky debt tax shield for the highly general class of Markovian debt adjustment policies. For a large set of dynamic debt policies, which have state-contingent (and hence risky) issuance and retirement of risk-free debt, we obtain closed-form solutions. For a still larger class of cases, we can point to a system of ordinary differential equations, which are easily solved numerically, that generate the tax shield's value.

The discount rate for unlevered cash flows that accounts for the debt tax shield is also of critical importance, both to practitioners and researchers. We study the theoretical underpinning of such a discount rate and relate it to the weighted average cost of capital. We can generally derive closed-form solutions for this discount rate whenever we have closed-form solutions for the debt tax shield. However, we also are able to show what adjustments are needed to convert the $W A C C$ to an appropriate discount rate. Such adjustments are almost always needed as the $W A C C$ is an appropriate discount rate only in the Modigliani-Miller and Miles-Ezzell cases, or in some linear hybrid of these two well-known cases.

Finally, we derive a formula for more general debt policies that characterizes the equity beta as a function of the leverage ratio and the unlevered asset beta. This formula generalizes the standard textbook formulas of Hamada (1972) and Miles and Ezzell (1985), which are associated with the Modigliani-Miller and Miles-Ezzell models, respectively.

Our approach differs from that found in prior research on debt tax shield valuation. In lieu of strong restrictions on cash flows, project values, asset values, discount rates, or debt policy, we impose restrictions on the information structure. Using the option pricing approach of Black-Scholes (1973) and Merton (1973), we assume that information follows a Markov diffusion process. The advantage of this information structure is that it makes the market dynamically complete. In our case, as long as the short-term risk-free rate and the discount rate (which can be any function of the information set) for an otherwise identical unlevered asset are specified, we can use the standard continuous-time valuation methodology to price any future payoff, be it a future cash flow generated by the unlevered asset or a tax shield from a complex, yet realistic, debt policy. Essentially, we are viewing the tax shield as a derivative of the underlying unlevered asset. We can write down a dynamic portfolio of the unlevered asset and a risk-free security that tracks the flow from the asset's debt tax shield for any reasonable dynamic debt policy. The no arbitrage condition, which is a partial differential equation, generates the value of the tax shield as a function of the value of the 
unlevered asset (or equivalently, the unlevered cash flow).

The no arbitrage valuation methodology of asset pricing theory has been applied before in a corporate setting, perhaps most elegantly by Ross (1978). However, interesting functional forms that link the interest tax deduction associated with an asset's financing mix to its unlevered cash flows provide economic insights that elude a more general framework. One example of this is a heuristic description of how the value of the debt tax shield, as well as the appropriate discount rate, vary with debt policies that can be viewed as weighted averages of the Modigliani-Miller and Miles-Ezzell debt policies.

Our paper also analyzes the discrete setting, but to a more limited extent. Here, when debt policies are linear functions of cash flows, we obtain closed-form solutions for the value of the debt tax shield.

Section I of the paper develops a general approach for valuing debt tax shields. It also analyzes an extraordinarily large class which has a closed-form solution for the tax shield and presents two larger classes of cases for which numerical computation of the value of the debt tax shield is trivial. Section II examines the weighted average cost of capital and relates it to valuation. It also characterizes how the $W A C C$ is affected by dynamic debt policies and studies when the $W A C C$ can be used to obtain valuations that properly account for the value of the debt tax shield. Finally, this section derives closed-form solutions for tax-adjusted discount rates that generate the correct valuations of cash flow streams. In most cases outside of the Modigliani-Miller and Miles-Ezzell frameworks, we show that these discount rates differ from the $W A C C$. Section III analyzes how to lever and unlever equity betas and equity risk premia for arbitrary debt policies. Section IV concludes the paper.

\section{The Valuation of Debt Tax Shields}

In a dynamically complete market, two assets with payoffs driven by the same source of uncertainty, and thus instantaneously perfectly correlated, can be valued in relation to one another. Just as an option is valued in relation to its underlying security, so too can a debt tax shield be valued in relation to the unlevered asset it is associated with. So long as the uncertainty behind the debt policy that generates the tax shield is tied only to uncertainty in the unlevered cash flows, debt tax shields are simply derivatives. For this reason, most of the paper assumes that the unlevered cash flow, the after-tax cash flow that would be generated in the absence of debt financing, satisfies a general Markov diffusion process.

An asset that is levered with risk-free debt has two sources of after-tax cash flow at date $t: 1)$ the unlevered cash flow, $X_{t} d t$, which is the after-tax flow that directly stems from the real asset, which is assumed to be unaffected by the asset's financing mix, and 2) the flow from the debt interest tax shield, $\tau_{c} D_{t} r_{f} d t$, which is the product of the tax rate $\tau_{c}$ and the 
debt interest payment $D_{t} r_{f} d t .^{2}$ Because valuation is linear, the value of a levered asset is the sum of the values of its two cash flow components.

For simplicity (and without loss of generality), we let one Brownian motion, $B$, drive the uncertainty. That is, between dates 0 and $T$, with $T$ possibly infinite,

$$
d X_{t}=g(t, X) X d t+\sigma(t, X) X d B_{t}
$$

With this assumption, the market is dynamically complete with two assets. ${ }^{3}$ This means that a dynamic trading strategy can transform a levered asset into an unlevered asset, and vice versa. Similarly, knowing the value of an asset for any given debt policy allows us to compute the value of its tax shield for all debt policies. Solutions can be found with a variety of mathematically equivalent approaches, but the most popular method involves the solution of a differential equation generated by Ito's Lemma and the principle of no arbitrage.

The continuous-time setting, described above, allows valuation of almost any derivative, including tax shields, by applying the well-known no arbitrage principle. Hence, the following assumptions are primarily used for expositional clarity and explicit solutions:

- The corporate tax rate, $\tau_{c}$, is constant.

- The risk-free interest rate, $r_{f}$, is constant. ${ }^{4}$

- There are no personal taxes, ${ }^{5}$ bankruptcy, or other market frictions associated with debt beyond the corporate tax (implying that the debt interest coupon rate equals the risk-free rate).

\footnotetext{
${ }^{2}$ In order for the levered asset to have the same investment policy in the presence of debt, we assume, without loss of generality, that the flow from the interest-based tax shield is paid out. It could be retained in a risk-free interest bearing account and distributed later, but this has tax consequences for the firm. In essence, such retention amounts to negative debt and it is the net debt policy for which we are computing the tax shield. Given this definition of how to account for debt, and appropriate care taken to avoid double counting when this cash is eventually distributed, our results apply irrespective of whether cash is retained or paid out.

${ }^{3} B$ can be a vector provided that the instantaneous changes in debt are perfectly correlated with instantaneous changes in $X$. If the unlevered cash flow has $J$ Brownian motion components and debt policy depends differently on each of them, our results still go through whenever we can value the levered assets at $J$ distinct debt levels. Alternatively, $J$ distinct securities can be used to value the tax shield. These could include equity, equity options, or comparable assets at the same or distinct debt levels.

${ }^{4}$ This implies that the risk-free yield curve is flat and nonstochastic. Debt maturity is irrelevant in our model.

${ }^{5}$ Personal taxes are clearly important for asset valuation and debt policy, as Green and Hollifield (2002) prove theoretically and document empirically. Their paper analyzes the optimal capital structure for a firm with a Modigliani-Miller debt policy, bankruptcy costs, and a cash distribution policy to equity holders that is sensitive to the economic effects of the corporate and capital gains taxes.
} 


\section{A. Debt Policy and Levered Asset Valuation: The General Case}

We begin by studying the valuation of a levered asset under a general class of debt policies. The debt policy $D$ can be any differentiable function of time $t$, unlevered cash flow $X$, levered asset value $V^{L}$, and history $H .^{6}$ That is,

$$
D_{t}=D\left(t, X_{t}, V_{t}^{L}, H_{t}\right)
$$

These general debt policies can depend, in a quite complicated manner, on the history of the asset, such as past cash flows, past debt values, past asset values, in addition to current cash flow and current asset value. We only require that the history dependence at a given date $t$ be summarized by additional date $t$ state variables. This allows us to maintain the Markovian setting. Without loss of generality, we simplify notation by treating these state variables as the single variable $H_{t} \cdot{ }^{7}$ As long as the uncertainty associated with the path of $X$ spans the relevant state space for $H$, we will still be able to value the debt tax shield as a function of the value of the unlevered assets. To maintain this desirable property, we assume that $H_{t}$ satisfies the diffusion

$$
\begin{aligned}
d H_{t} & =\mu_{H}\left(t, X_{t}, D_{t}, V_{t}^{L}\right) d t+\sigma_{H}\left(t, X_{t}, D_{t}, V_{t}^{L}\right) d X_{t} \\
& =\mu_{h}\left(t, X_{t}, D_{t}, V_{t}^{L}\right) d t+\sigma_{h}\left(t, X_{t}, D_{t}, V_{t}^{L}\right) d B_{t}
\end{aligned}
$$

where

$$
\mu_{h}\left(t, X_{t}, D_{t}, V_{t}^{L}\right)=\mu_{H}\left(t, X_{t}, D_{t}, V_{t}^{L}\right)+\sigma_{H}\left(t, X_{t}, D_{t}, V_{t}^{L}\right) g\left(t, X_{t}\right) X_{t}
$$

and

$$
\sigma_{h}\left(t, X_{t}, D_{t}, V_{t}^{L}\right)=\sigma_{H}\left(t, X_{t}, D_{t}, V_{t}^{L}\right) \sigma\left(t, X_{t}\right) X_{t} .
$$

Recognize that the functional form of the exogenously specified $\mu_{h}$ and $\sigma_{h}$ can be quite general. It would be difficult to imagine any empirically relevant debt policy that could not be captured with this flexibility.

Given this description of debt policy and history, it follows that the date $t$ value of the levered asset, $V_{t}^{L}=V^{L}\left(t, X_{t}, H_{t}\right)$, depends on the current date, cash flow, and history. Moreover, if the unlevered cash flow stream terminates at date $T$, (essentially, becomes zero at date $T$ and forever thereafter), the functional form of the valuation function will be influenced by the proximity to the termination date.

\footnotetext{
${ }^{6}$ The optimal debt policy, while a critical issue both in formulating $D_{t}$ and the value of the tax shield, is beyond the scope of this paper. A continuous-time model with closed-form solutions for the optimal debt level when bankruptcy costs are traded off against a Modigliani-Miller debt policy is found in Leland's (1994) seminal research. In our paper, because debt can be adjusted continuously, firms can avoid bankruptcy with certainty.

${ }^{7}$ We can also regard $H$ and the coefficients in its diffusion as vectors with virtually no change to any of our equations.
} 
In the absence of arbitrage, dynamic completeness implies that this value necessarily satisfies the partial differential equation (PDE)

$$
\begin{aligned}
& \frac{\partial V^{L}}{\partial t}+(g-\eta) X \frac{\partial V^{L}}{\partial X}+\frac{1}{2} \sigma^{2} X^{2} \frac{\partial^{2} V^{L}}{\partial X^{2}}-r_{f} V^{L} \\
& +\left(\mu^{h}-\eta \sigma_{h}\right) \frac{\partial V^{L}}{\partial H}+\frac{1}{2} \sigma_{h}^{2} \frac{\partial^{2} V^{L}}{\partial H^{2}}+\sigma \sigma^{h} \frac{\partial^{2} V^{L}}{\partial H \partial X} X=-\left(X+r_{f} \tau_{c} D\right) .
\end{aligned}
$$

where we have dropped the arguments of $g, \sigma$, etc. for notational simplicity. If the asset has a finite life, the terminal condition is

$$
V^{L}\left(T, X_{T}, H_{T}\right)=0
$$

This partial differential equation, a familiar extension of the well-known Black-Scholes differential equation, is simply the no arbitrage condition associated with an asset whose uncertainty is spanned by the payoff to a dynamic trading strategy in the unlevered asset and a risk-free security. The $\eta(t, X)$ term in equation (1), (shortened to $\eta$ for notational simplicity), is the premium per unit of risk generated by changes in $B$. In a corporate setting, it would be traditional to think of this parameter as being determined by the instantaneous discount rate of the unlevered asset. However, $\eta$ also can be inferred from the levered asset's value for any debt policy.

To derive the partial differential equation, note that Ito's Lemma implies that the change in the value of a levered asset plus all distributions of cash flow:

$$
\begin{aligned}
d V_{t}^{L}+\left(X_{t}+r_{f} \tau_{c} D_{t}\right) d t & =\frac{\partial V^{L}}{\partial t} d t+\frac{\partial V^{L}}{\partial X} d X+\frac{\partial V^{L}}{\partial H} d H \\
& +\left(\frac{1}{2} \frac{\partial^{2} V^{L}}{\partial X^{2}} \sigma^{2} X^{2}+\frac{\partial^{2} V^{L}}{\partial H \partial X} \sigma \sigma_{h}+\frac{1}{2} \frac{\partial^{2} V^{L}}{\partial H^{2}} \sigma_{h}^{2}\right) d t+\left(X_{t}+r_{f} \tau_{c} D_{t}\right) d t \\
& =\left(\frac{\partial V^{L}}{\partial t}+\frac{\partial V^{L}}{\partial X} g X+\frac{\partial V^{L}}{\partial H} \mu_{h}\right) d t \\
& +\left(\frac{1}{2} \frac{\partial^{2} V^{L}}{\partial X^{2}} \sigma^{2} X^{2}+\frac{\partial^{2} V^{L}}{\partial H \partial X} \sigma \sigma_{h} X+\frac{1}{2} \frac{\partial^{2} V^{L}}{\partial H^{2}} \sigma_{h}^{2}+X_{t}+r_{f} \tau_{c} D_{t}\right) d t \\
& +\left(\frac{\partial V^{L}}{\partial X}+\frac{\partial V^{L}}{\partial H} \sigma_{H}\right) \sigma X d B
\end{aligned}
$$

The analogous equation for an otherwise identical unlevered asset with date $t$ value $V_{t}^{U}=V^{U}(t, X)$ is

$$
\begin{aligned}
d V_{t}^{U}+X_{t} d t & =\left(\frac{\partial V^{U}}{\partial t}+\frac{\partial V^{U}}{\partial X} g X+\frac{1}{2} \frac{\partial^{2} V^{U}}{\partial X^{2}} \sigma^{2} X^{2}+X_{t}\right) d t+\frac{\partial V^{U}}{\partial X} X \sigma d B \\
& =\left(V^{U} r_{f}+\frac{\partial V^{U}}{\partial X} X \eta\right) d t+\frac{\partial V^{U}}{\partial X} X \sigma d B
\end{aligned}
$$


where $\eta$, defined by its placement above, is simply a convenient symbol for a scaling of the risk premium attached to $d B$. We can express $\eta$ in terms of the instantaneous unlevered cost of capital, $r_{t}^{U}$ as

$$
\eta(t, X)=\frac{r_{t}^{U}-r_{f}}{\frac{\partial \ln \left(V_{t}^{U}\right)}{\partial \ln \left(X_{t}\right)}} .
$$

Clearly, instantaneous changes in $V^{L}$ and $V^{U}$ are perfectly correlated. Thus, to prevent arbitrage, the ratios of the risk premia per dollar invested in the levered and unlevered assets must be proportional to the risk born per dollar invested in each of the assets. This implies

$$
\begin{aligned}
\frac{\partial V^{L}}{\partial t}+\frac{\partial V^{L}}{\partial X} g X+\frac{\partial V^{L}}{\partial H} \mu_{h} & +\frac{1}{2} \frac{\partial^{2} V^{L}}{\partial X^{2}} \sigma^{2} X^{2}+\frac{\partial^{2} V^{L}}{\partial H \partial X} \sigma \sigma_{h} X+\frac{1}{2} \frac{\partial^{2} V^{L}}{\partial H^{2}} \sigma_{h}^{2}+X_{t}+r_{f} \tau_{c} D_{t}-r_{f} V_{L} \\
& =\left(\frac{\partial V^{L}}{\partial X}+\frac{\partial V^{L}}{\partial H} \sigma_{H}\right) X \eta
\end{aligned}
$$

which, when rearranged, gives us equation (1). In analogous fashion, the value of the taxshield $\Delta=V^{L}-V^{U}$ satisfies the PDE

$$
\begin{aligned}
& \frac{\partial \Delta}{\partial t}+(g-\eta) X \frac{\partial \Delta}{\partial X}+\frac{1}{2} \sigma^{2} X^{2} \frac{\partial \Delta}{\partial X^{2}}-r_{f} \Delta \\
& +\left(\mu^{h}-\eta \sigma_{H}\right) \frac{\partial \Delta}{\partial H}+\frac{1}{2} \sigma_{h}^{2} \frac{\partial^{2} \Delta}{\partial H^{2}}+\sigma \sigma_{h} \frac{\partial^{2} \Delta}{\partial H \partial X} X=-r_{f} \tau_{c} D
\end{aligned}
$$

In principle, these partial differential equations can be solved. However, without further restrictions, these differential equations are difficult to solve, even numerically. Hence, the remainder of this section explores cases where solutions are insightful or, from a numerical perspective, quickly attainable. Essentially, whenever we can transform the PDE into an ordinary differential equation (ODE), numerical solutions are easily found. We explore two such classes of cases. In the first, all of the model's parameters depend only on the contemporaneous level of the unlevered cash flow, $X$. Here, because there is no time dependence, equation (1) reduces to an ordinary differential equation in $X$. In the second class of cases, which we refer to as "Additively Separable Assets," the levered asset value is additively separable in a set of arguments, which consist of $H$ and a finite collection of real powers of $X: X^{\lambda_{1}}, X^{\lambda_{2}}, \ldots, X^{\lambda_{N}}$. The coefficients of these arguments may be time dependent. The additively separable class of cases is particularly interesting for its ability to generate remarkably general closed-form solutions for the value of the debt tax shield. These apply to both finite-lived and perpetual assets. They arise whenever the $N$ cash flow coefficients of the value additive functions for debt and history are growing at constant exponential rates and the remaining coefficients are constant. Given this level of generality, it appears as if our closed-form solutions could generate fairly good approximations for the value of a debt tax shield for most conceivable debt policies. 


\section{B. Cash Flows and Debt with Time Independent Parameters}

When the parameters of the dynamic process for $X$ do not depend explicitly on time $t$ (that is, $g(t, X)=g(X), \sigma(t, X)=\sigma(X)$, and $\eta(t, X)=\eta(X))$ and the debt policy $D$ does not depend on either time $t$ or the history $H_{t}$, the asset value $V^{L}$ depends only on the contemporaneous cash flow level, $X$. In this case, the PDE for the value of the levered asset (1) becomes the second order ODE:

$$
(g(X)-\eta(X)) \frac{\partial V^{L}}{\partial X}+\frac{1}{2} \sigma^{2}(X) X^{2} \frac{\partial^{2} V^{L}}{\partial X^{2}}-r_{f} V^{L}=-\left(X+r_{f} \tau_{c} D(X)\right) .
$$

which is trivial to solve numerically for any specification of $g(X), \sigma(X)$, and $\eta(X){ }^{8}$ Special cases with closed-form solutions include the continuous-time versions of the ModiglianiMiller debt policy $\left(g(X)=0, \eta(X)=\eta\right.$ and $D(X)=D$ implying $V^{U}=X /\left(r_{f}+\eta\right)$ and $\left.V^{L}=V^{U}+\tau_{c} D\right)$ and the Miles-Ezzell debt policy, $\left(g(X)=0, \eta(X)=\eta\right.$ and $D(X)=d^{x} X$, with $d^{x}$ constant, implying $V^{U}=X /\left(r_{f}+\eta\right)$ and $\left.V^{L}=V^{U}+\tau_{c} D r_{f} /\left(r_{f}+\eta\right)\right)$. We defer further discussion of this as the class of debt policies analyzed next also includes the ModiglianiMiller and Miles-Ezzell models as special cases.

\section{Additively Separable Assets: Numerical Solutions}

Additively separable assets have tax shields with values that are additively separable linear functions of history, $H$, and any set of real powers of the cash flow, $X^{\lambda}$. Simple examples of additively separable assets include the constant coefficient quadratic case,

$$
V_{t}^{L}=V_{t}^{U}+c_{0}^{x}+c_{1}^{x} X_{t}+c_{2}^{x} X_{t}^{2}
$$

which is generated by the constant coefficient history-independent quadratic debt policy

$$
D_{t}=d_{0}^{x}+d_{1}^{x} X_{t}+d_{2}^{x} X_{t}^{2}
$$

and the constant coefficient square root case,

$$
V_{t}^{L}=V_{t}^{U}+c_{0}^{x}+c_{1 / 2}^{x} \sqrt{X_{t}}
$$

which is generated by the constant coefficient history-independent square root debt policy

$$
D_{t}=d_{0}^{x}+d_{1 / 2}^{x} \sqrt{X_{t}}
$$

\footnotetext{
${ }^{8}$ Any two boundary conditions, which implicitly determine the debt level in all states of the world, determine a unique solution to the differential equation. Hence, specifying the debt policy is clearly sufficient for obtaining the levered asset's value.
} 
A more complicated case arises when the debt level is history dependent with history given by

$$
\begin{aligned}
H_{t} & =H_{0} e^{-m^{h} t-\frac{1}{2}\left(l^{h}\right)^{2} t-l^{h} B_{t}}+m^{x} \int_{0}^{t} e^{-m^{h}(t-s)-\frac{l}{2}\left(l^{h}\right)^{2}(t-s)-l^{h}\left(B_{s}-B_{t}\right)} X_{s} d s \\
& +m^{d} \int_{0}^{t} e^{-m^{h}(t-s)-\frac{1}{2}\left(l^{h}\right)^{2}(t-s)-l^{h}\left(B_{s}-B_{t}\right)} D_{s} d s+m^{v} \int_{0}^{t} e^{-m^{h}(t-s)-\frac{1}{2}\left(l^{h}\right)^{2}(t-s)-l^{h}\left(B_{s}-B_{t}\right)} V_{s}^{L} d s \\
& +l^{x} \int_{0}^{t} e^{-m^{h}(t-s)-\frac{1}{2}\left(l^{h}\right)^{2}(t-s)-l^{h}\left(B_{s}-B_{t}\right)} X_{s} d B_{s}+l^{d} \int_{0}^{t} e^{-m^{h}(t-s)-\frac{1}{2}\left(l^{h}\right)^{2}(t-s)-l^{h}\left(B_{s}-B_{t}\right)} D_{s} d B_{s} \\
& +l^{v} \int_{0}^{t} e^{-m^{h}(t-s)-\frac{1}{2}\left(l^{h}\right)^{2}(t-s)-l^{h}\left(B_{s}-B_{t}\right)} V_{s}^{L} d B_{s} .
\end{aligned}
$$

In this special case, the diffusion process for $H_{t}$ satisfies

$$
d H_{t}=\left(m^{x} X_{t}+m^{d} D_{t}+m^{v} V_{t}^{L}-m^{h} H_{t}\right) d t+\left(l^{x} X_{t}+l^{d} D_{t}+l^{v} V_{t}^{L}-l^{h} H_{t}\right) d B_{t},
$$

and thus has drift and volatility of

$$
\mu_{h}=m^{x} X_{t}+m^{d} D_{t}+m^{v} V_{t}^{L}-m^{h} H_{t}, \quad \sigma_{h}=l^{x} X_{t}+l^{d} D_{t}+l^{v} V_{t}^{L}-l^{h} H_{t} .
$$

This history process, with the $m s$ and $l$ s constant, when combined with an analogous functional form for the debt process, leads to a closed-form additively separable solution for the value of the debt tax shield, as we show in the next subsection.

The most general class of additively separable assets has history diffusion and debt policy of the form:

$$
\begin{aligned}
d H_{t} & =\left(\sum_{\lambda} m_{\lambda}^{x}(t) X_{t}^{\lambda}+m^{v}(t) V_{t}^{L}+m^{d}(t) D_{t}-m^{h}(t) H_{t}\right) d t \\
& +\left(\sum_{\lambda} l_{\lambda}^{x}(t) X_{t}^{\lambda}+l^{v}(t) V_{t}^{L}+l^{d}(t) D_{t}-l^{h}(t) H_{t}\right) d B_{t}
\end{aligned}
$$

and

$$
D_{t}=\sum_{\lambda} d_{\lambda}^{x}(t) X_{t}^{\lambda}+d^{v}(t) V_{t}^{L}+d^{h}(t) H_{t}
$$

along with risk premia, $\eta(t)$, unlevered cash flow growth rate, $g(t)$, and volatilities, $\sigma(t)$ and $\sigma_{H}(t)$, that depend only on time. An implication of $g(t)$ and $\eta(t)$ depending only on time is that the "price-earnings ratio" for an unlevered asset, $y_{t}^{U}=V_{t}^{U} / X_{t}$, depends only on time. ${ }^{9}$

\footnotetext{
${ }^{9}$ To prove this, note that $X_{t}$ drops out of the ratio

$$
\frac{V_{t}^{U}}{X_{t}}=\int_{t}^{T} e^{\int_{t}^{s} g(\omega) d \omega} e^{-\int_{t}^{s} r_{\omega}^{U} d \omega} d s
$$
}


One can show that the value of a levered asset with debt policy and history satisfying these properties is of the additively separable form

$$
V_{t}^{L}=V_{t}^{U}+\sum_{\lambda} c_{\lambda}^{x}(t) X_{t}^{\lambda}+c^{h}(t) H_{t}
$$

and the PDE, equation (1), is of the form ${ }^{10}$

$$
\begin{aligned}
& \sum_{\lambda} \frac{\partial c_{\lambda}^{x}}{\partial t} X^{\lambda}+\frac{\partial c^{h}}{\partial t} H+(g-\eta) \sum_{\lambda} \lambda c_{\lambda}^{x} X^{\lambda}+\frac{1}{2} \sigma^{2} \sum_{\lambda} c_{\lambda}^{x} \lambda(\lambda-1) X^{\lambda} \\
& +\left[-\left(k^{h}-k^{d} d^{h}-\left(k^{v}+k^{d} d^{v}\right) c^{h}\right) H+\sum_{\lambda}\left(k_{\lambda}^{x}+k^{d} d_{\lambda}^{x}+\left(k^{v}+k^{d} d^{v}\right) c_{\lambda}^{x}\right) X^{\lambda}+\left(k^{v}+k^{d} d^{v}\right) V^{U}\right] c^{h} \\
& -r_{f}\left(\sum_{\lambda} c_{\lambda}^{x} X^{\lambda}+c^{h} H\right)=-r_{f} \tau_{c}\left[\sum_{\lambda} d_{\lambda}^{x} X^{\lambda}+d^{v}\left(V^{U}+\sum_{\lambda} c_{\lambda}^{x} X^{\lambda}+c^{h} H\right)+d^{h} H\right]
\end{aligned}
$$

with $k^{q}=m^{q}-\eta l^{q}$ for $q \in\{x, d, v, h\}$.

Equating the coefficients of $H$ and $X^{\lambda}$ on each side produces $N+1$ ordinary differential equations with $N$ being the number of powers of $X$ that appear in the debt and history equations:

$$
\begin{aligned}
\frac{d c_{\lambda}^{x}}{d t}+ & (g-\eta) \lambda c_{\lambda}^{x}+\frac{1}{2} \sigma^{2} c_{\lambda}^{x} \lambda(\lambda-1)+\left(k_{\lambda}^{x}+k^{d} d_{\lambda}^{x}+\left(k^{v}+k^{d} d^{v}\right) c_{\lambda}^{x}+\left(k^{v}+k^{d} d^{v}\right) y_{t}^{U} \delta_{\lambda, 1}\right) c^{h} \\
& -r_{f} c_{\lambda}^{x}+r_{f} \tau_{c}\left(d_{\lambda}^{x}+d^{v} c_{\lambda}^{x}+d^{v} y_{t}^{U} \delta_{\lambda, 1}\right)=0 \\
\frac{d c^{h}}{d t}- & \left(k^{h}-k^{d} d^{h}-\left(k^{v}+k^{d} d^{v}\right) c^{h}\right) c^{h}-r_{f} c^{h}+r_{f} \tau_{c}\left(d^{v} c^{h}+d^{h}\right)=0
\end{aligned}
$$

with $\delta_{1, \lambda}$ a binary variable that takes on the value 1 if $\lambda=1$ and 0 otherwise, ${ }^{11}$ and with the terminal condition given by

$$
c_{\lambda}^{x}(T)=c^{h}(T)=0 .
$$

This system of Riccati equations is easily solved numerically. However, there are large classes of cases that have closed-form solutions. We explore these below.

\section{Additively Separable Assets with Closed-Form Solutions}

Suppose that each of the coefficients $k^{d}(t), k^{v}(t), k^{h}(t), d^{v}(t), d^{h}(t)$ are constant and

$$
\begin{aligned}
& k_{\lambda}^{x}(t)=k_{\lambda}^{x}(0) e^{g_{\lambda}^{k} t} \\
& d_{\lambda}^{x}(t)=d_{\lambda}^{x}(0) e^{g_{\lambda}^{d} t}
\end{aligned}
$$

\footnotetext{
${ }^{10}$ Note that many of terms involving $V^{U}$ cancel because of the no arbitrage PDE for $V^{U}$.

${ }^{11}$ Without loss of generality, and only for notational simplicity, we assume that one of the powers of $\lambda$ is $\lambda=1$ if one of $d^{v}, k^{v}, d_{1}^{x}$, or $k_{1}^{x}$ is non-zero. Also, note that if $\lambda_{i}=0$, we have an exponentially growing constant term. We explore a special case with this feature later.
} 
with the constant growth parameters $g_{\lambda}^{k}$ and $g_{\lambda}^{d}$ possibly 0 . For expositional clarity, we also assume that the mean and volatility of the unlevered cash flow growth rate, as well as the market price of risk, are constant. That is, $g(t, X)=g, \sigma(t, X)=\sigma$, and $\eta(t, X)=\eta$. This allows us to express the value of an unlevered asset with the growing annuity formula, as in the Gordon Growth Model:

$$
V_{t}^{U}=\frac{X_{t}}{r^{U}-g}\left(1-e^{-\left(r^{U}-g\right)(T-t)}\right)
$$

The Gordon growth assumptions imply that $\frac{\partial \ln \left(V_{t}^{U}\right)}{\partial \ln \left(X_{t}\right)}=1$ and that the risk premium on the unlevered asset $r^{U}-r_{f}=\eta$.

We could allow $g, \sigma$, and $\eta$ to be deterministic functions of time and still achieve solutions similar to those developed below but at the cost of expressions with confusing sets of integrals in them. As this discussion is about the valuation of tax shields for complex debt policies, and not about the complexities of valuation in a no-tax setting, we opt for an approach that makes the latter valuation as uncomplicated as possible.

Under these assumptions, the system of Riccati equations is solved by

$$
c^{h}(t)=\frac{1-e^{-b(T-t)}}{1-\frac{c_{\infty}^{h}}{c_{\infty}^{h}+b / a} e^{-b(T-t)}} c_{\infty}^{h},
$$

where $^{12}$

$$
\begin{aligned}
a & =k^{v}+k^{d} d^{v}, \\
b & =\sqrt{\left(k^{h}-k^{d} d^{h}+r_{f}\left(1-\tau_{c} d^{v}\right)\right)^{2}-4 a \tau_{c} r_{f} d^{h}}, \\
c_{\infty}^{h} & =\frac{\sqrt{b^{2}+4 a \tau_{c} r_{f} d^{h}}-b}{2 a}
\end{aligned}
$$

and for $\lambda=\lambda_{1}, \ldots, \lambda_{N}$

$$
\begin{aligned}
c_{\lambda}^{x}(t) & =r_{f} \tau_{c} d_{\lambda}^{x}(t) \mathcal{C}_{1}\left(g_{\lambda}^{d}\right)+\frac{r_{f} \tau_{c} d^{v}}{r^{U}-g} \delta_{\lambda, 1}\left(\mathcal{C}_{1}(0)-e^{-\left(r^{U}-g\right)(T-t)} \mathcal{C}_{1}\left(r^{U}-g\right)\right)+k_{\lambda}^{x}(t) \mathcal{C}_{2}\left(g_{\lambda}^{k}\right) \\
& +k^{d} d_{\lambda}^{x}(t) \mathcal{C}_{2}\left(g_{\lambda}^{d}\right)+\frac{a}{r^{U}-g} \delta_{\lambda, 1}\left(\mathcal{C}_{2}(0)-e^{-\left(r^{U}-g\right)(T-t)} \mathcal{C}_{2}\left(r^{U}-g\right)\right),
\end{aligned}
$$

where

$$
\begin{aligned}
& C_{1}(z)=\frac{1}{1-\frac{c_{\infty}^{h}}{c_{\infty}^{h}+b / a} e^{-b(T-t)}}\left[\frac{1-e^{-\left(g_{\lambda}^{x}-z\right)(T-t)}}{g_{\lambda}^{x}-z}-e^{-b(T-t)} \frac{c_{\infty}^{h}}{c_{\infty}^{h}+b / a}\left(\frac{1-e^{-\left(g_{\lambda}^{x}-z-b\right)(T-t)}}{g_{\lambda}^{x}-z-b}\right)\right] \\
& C_{2}(z)=\frac{c_{\infty}^{h}}{1-\frac{c_{\infty}^{h}}{c_{\infty}^{h}+b / a} e^{-b(T-t)}}\left[\frac{1-e^{-\left(g_{\lambda}^{x}-z\right)(T-t)}}{g_{\lambda}^{x}-z}-e^{-b(T-t)}\left(\frac{1-e^{-\left(g_{\lambda}^{x}-z-b\right)(T-t)}}{g_{\lambda}^{x}-z-b}\right)\right]
\end{aligned}
$$

\footnotetext{
${ }^{12}$ For the tax shield of a finite-lived asset to have a finite value, $b$, given below, has to be a real number. Also, for history to be stable, $k^{h}-k^{d} d^{h}+r_{f}\left(1-\tau_{c} d^{v}\right)$ has to be positive. Throughout the paper, we assume that parameters satisfy the transversality conditions so that the debt tax shield is finite.
} 
with $g_{\lambda}^{x}$ defined by

$$
g_{\lambda}^{x}=r_{f}\left(1-\tau_{c} d^{v}\right)-\left(k^{v}+k^{d} d^{v}\right) c_{\infty}^{h}+(\eta-g) \lambda-\frac{1}{2} \sigma^{2} \lambda(\lambda-1) .
$$

\section{Case 1: Perpetual Assets}

As $T \rightarrow \infty$, equation (4) becomes

$$
c^{h}(t)=c_{\infty}^{h}
$$

and the $N$ cash flow coefficients given by equation (5) simplify to

$$
c_{\lambda}^{x}(t)=\frac{k_{\lambda}^{x}(t) c_{\infty}^{h}}{g_{\lambda}^{x}-g_{\lambda}^{k}}+\frac{\left(r_{f} \tau_{c}+k^{d} c_{\infty}^{h}\right) d_{\lambda}^{x}(t)}{g_{\lambda}^{x}-g_{\lambda}^{d}}+\frac{a c_{\infty}^{h}+r_{f} \tau_{c} d^{v}}{\left(r^{U}-g\right)\left(r_{f}\left(1-\tau_{c} d^{v}\right)+\eta-g\right)} \delta_{\lambda, 1},
$$

since, as $T \rightarrow \infty$,

$$
\begin{aligned}
C_{1}(z) & =\frac{c_{\infty}^{h}}{g_{\lambda}^{x}-z} \\
C_{2}(z) & =\frac{1}{g_{\lambda}^{x}-z} .
\end{aligned}
$$

This implies

$V_{t}^{L}=\left(1+\frac{a c_{\infty}^{h}+r_{f} \tau_{c} d^{v}}{r_{f}\left(1-\tau_{c} d^{v}\right)+\eta-g}\right) V_{t}^{U}+\sum_{\lambda}\left(\frac{k_{\lambda}^{x}(t) c_{\infty}^{h}}{g_{\lambda}^{x}-g_{\lambda}^{k}}+\frac{\left(r_{f} \tau_{c}+k^{d} c_{\infty}^{h}\right) d_{\lambda}^{x}(t)}{g_{\lambda}^{x}-g_{\lambda}^{d}}\right) X_{t}^{\lambda}+c_{\infty}^{h} H_{t}$.

\section{Case 2: Perpetual Debt as a Function of Cash Flows Only}

When $T \rightarrow \infty$ and $d^{v}=d^{h}=0, c_{\infty}^{h}=0$. In this case, the solution for Case 1 simplifies to

$$
c_{\lambda}^{x}(t)=\frac{r_{f} \tau_{c} d_{\lambda}^{x}(t)}{g_{\lambda}^{x}-g_{\lambda}^{d}}
$$

implying

$$
V_{t}^{L}=V_{t}^{U}+\sum_{\lambda} \frac{r_{f} \tau_{c}}{r_{f}+(\eta-g) \lambda-\frac{1}{2} \sigma^{2} \lambda(\lambda-1)-g_{\lambda}^{d}} d_{\lambda}^{x}(t) X_{t}^{\lambda} .
$$

\section{Case 3: Debt that is a Linear Function of Asset Value Plus Constant Growth} For this special case,

$$
D_{t}=d_{0}^{x}(0) e^{g_{0}^{d} t}+d^{v} V_{t}^{L}
$$

with the sensitivity of debt to asset value constant; that is, $d^{v}(t)=d^{v}$. The remaining coefficients are zero. Note that the constant growth rate component in debt, $g_{0}^{d}$, may differ 
from $g$, the expected growth rate in cash flows. When $d^{v}$ is zero, debt grows at the constant geometric rate of $g_{0}^{d}$ (possibly zero). When $d_{0}^{x}(0)=0$, the debt to asset ratio is constant over the life of the asset. Hence, this policy, as well as the stationary model described in the prior subsection, nests both the Modigliani-Miller and Miles-Ezzell debt policies. (Note that if $d^{v}$ is nonzero, the expected growth rate in debt is influenced both by the expected growth rate in $V^{L}$ as well as $g_{0}^{d}$.)

This is a case where $c^{h}(t)=c_{\infty}^{h}=C_{2}(z)=0$ and the solution reduces to

$$
V_{t}^{L}=V_{t}^{U}+c_{0}^{x}(t)+c_{1}^{x}(t) X_{t}
$$

with the values for $c_{\lambda}^{x}$ from equation (5) becoming

$$
\begin{aligned}
& c_{0}^{x}(t)=r_{f} \tau_{c} d_{0}^{x}(t)\left(\frac{1-e^{-\left(r_{f}\left(1-\tau_{c} d^{v}\right)-g_{0}^{d}\right)(T-t)}}{r_{f}\left(1-\tau_{c} d^{v}\right)-g_{0}^{d}}\right) \\
& c_{1}^{x}(t)=\frac{r_{f} \tau_{c} d^{v}}{r^{U}-g}\left(\frac{1-e^{-\left(r_{f}\left(1-\tau_{c} d^{v}\right)+\eta-g\right)(T-t)}}{r_{f}\left(1-\tau_{c} d^{v}\right)+\eta-g}\right)
\end{aligned}
$$

A particularly simple expression exists for a perpetual levered asset in Case 3. Here, the coefficients above imply ${ }^{13}$

$$
V_{t}^{L}=V_{t}^{U}+\tau_{c}\left(\frac{r_{f}}{r_{f}\left(1-\tau_{c} d^{v}\right)-g_{0}^{d}} d_{0}^{x}(t)+\frac{r_{f}}{r_{f}\left(1-\tau_{c} d^{v}\right)+\eta-g} d^{v} V_{t}^{U}\right)
$$

Note that when $g=g_{0}^{d}=d^{v}=0$, equation (6) is the Modigliani-Miller value,

$$
\begin{aligned}
V_{t}^{L} & =V_{t}^{U}+\tau_{c} d_{0}^{x}(t) \\
& =V_{t}^{U}+\tau_{c} D_{t} .
\end{aligned}
$$

When $d^{v}$ is zero but $g_{0}^{d}$ and $g$ are nonzero, we have an extension of the Modigliani-Miller debt policy that allows for growing debt and unlevered cash flows that are expected to grow. As we will learn in the next section of the paper on the $W A C C$, the initial weighted average cost of capital, used as a discount rate, does not generate this value as the value of the levered asset when $g_{0}^{d} \neq g$. However, there is a simple adjustment to the $W A C C$ that generates the correct levered asset value.

${ }^{13}$ One can also map $D_{t}$ into $V_{t}^{L}$. A small amount of algebraic manipulation reveals

$$
V_{t}^{L}=V_{t}^{U}+\frac{r_{f}}{r_{f}-g_{0}^{d}} \tau_{c}\left(D_{t}+\frac{g-\eta-g_{0}^{d}}{r_{f}\left(1-\tau_{c} d^{v}\right)+\eta-g} d^{v} V_{t}^{U}\right)
$$

Thus, the value of the debt tax shield is the sum of the Modigliani-Miller debt tax shield (with constantly growing debt) and a term which may be positive or negative. The sign of the final term in parentheses depends on whether $g-\eta$, the risk-adjusted growth rate of the unlevered cash flows, is larger than $g_{0}^{d}$, the growth rate for the nonstochastic debt component. 
When $d_{0}^{x}(t)=0$, debt policy is an extension of the continuous-time Miles and Ezzell debt policy that allows for cash flows with nonzero expected growth. In this case, equation (6) indicates that there is a proportional relationship between the value of a levered asset and its otherwise identical unlevered counterpart:

$$
V_{t}^{L}=\frac{r_{f}+\eta-g}{r_{f}\left(1-\tau_{c} d^{v}\right)+\eta-g} V_{t}^{U}
$$

implying

$$
V_{t}^{L}=V_{t}^{U}+\frac{r_{f}}{r_{f}+\eta-g} \tau_{c} D_{t}
$$

If $g_{0}^{d}=g$, the debt tax shield can be written as a simple weighted average of the tax shields for the Miles-Ezzell constant leverage ratio debt policy and the extended Modigliani-Miller debt policy (with possibly growing debt). In this case, equation (6) reduces to

$$
V_{t}^{L}=V_{t}^{U}+w_{t} \frac{r_{f}}{r_{f}-g} \tau_{c} D_{t}+\left(1-w_{t}\right) \frac{r_{f}}{r_{f}+\eta-g} \tau_{c} D_{t}
$$

where the weight

$$
w_{t}=\frac{r_{f}-g}{r_{f}\left(1-\tau_{c} d^{v}\right)-g}\left(1-\frac{d^{v}}{D_{t} / V_{t}^{L}}\right) .
$$

This weight is monotonically decreasing in $d^{v}$, the sensitivity of debt to the value of the asset, holding $D_{t}$ fixed. ${ }^{14}$

The Modigliani-Miller debt tax shield, which multiplies $w_{t}$ above, has a smaller value than its Miles-Ezzell counterpart, which multiplies $\left(1-w_{t}\right)$ above. ${ }^{15}$ Hence, for the same initial debt level, increasing the debt sensitivity coefficient, $d^{v}$, while holding the initial debt level fixed, reduces the value of the tax shield. This is because the value of the debt tax shield falls when its risk increases, other things equal. If the debt sensitivity coefficient, $d^{v}$, exceeds $D_{t} / V_{t}^{L}$, so that $w_{t}$ is negative, the leverage ratio will rise as the asset's value increases and fall when it decreases. In this case, the value of the asset will be below that obtained with the constant leverage ratio Miles-Ezzell debt policy. Conversely, if $d^{v}$ is negative, so that some of the existing debt is retired when the asset's value rises, ${ }^{16}$ and debt is issued when the asset's value declines, the value of the debt tax shield will be above the $\tau_{c} D_{t}$ value proposed by Modigliani and Miller. This confirms the intuition in Grinblatt and Titman (1997, 2002) and suggests that the appropriate discount rate for unlevered cash flows will be

\footnotetext{
${ }^{14}$ To see this, it is necessary to obtain an equation for the weight without $V_{t}^{L}$. This is accomplished by substituting the former equation into the latter and solving for $w_{t}$.

${ }^{15}$ This and the statements that follow from it assume that $\eta$, the risk premium for the unlevered cash flow, is positive. If the unlevered cash flow has a negative risk premium, the Miles-Ezzell value exceeds the Modigliani-Miller value.

${ }^{16}$ This debt paydown pattern has been estimated in empirical work by Kaplan and Stein (1990).
} 
a weighted average of the $W A C C$ s proposed by Miles and Ezzell and Modigliani and Miller. For $d^{v}>D_{t} / V_{t}^{L}$, the weight on the Modigliani-Miller $W A C C$ must be negative, for $d^{v}<0$, it is above 1 , and otherwise, it lies between 0 and 1 . As we will show later, the weighting on the $W A C C$ formulas of Modigliani-Miller and Miles-Ezzell is identical to the weighting of the respective tax shields given here.

The linear debt policy in Case 3 easily extends to discrete time. The linearity implies that over any discrete interval, the levered asset is a fixed-weight portfolio of an otherwise identical unlevered asset and a risk-free security. In this case, the values of the levered and unlevered assets are perfectly correlated, as both are linear functions of the cash flow. Solving the difference equations that generate the no arbitrage value of the levered asset in an analogous manner yields the discrete time analogue to equation (6): ${ }^{17}$

$V_{t}^{L}=V_{t}^{U}+\tau_{c}\left(\frac{r_{f}}{r_{f}\left(1-\tau_{c} d^{v}\right)-g_{0}^{d}} d_{0}^{x}(t)+\frac{r_{f}\left(1+r_{f}+\eta\right)}{\left(1+r_{f}\right)\left(r_{f}\left(1-\tau_{c} d^{v}\right)+\eta-g\right)-\eta r_{f} \tau_{c} d^{v}} d^{v} V_{t}^{U}\right)$.

This valuation solution nests both the discrete-time Modigliani-Miller and Miles-Ezzell debt policies as special cases.

The discrete case valuation formula, provided above, applies only to an infinitely-lived asset. A similar approach generates a discrete time closed-form solution for a finite-lived asset. It is omitted for the sake of brevity.

\section{Tax-Adjusted Discount Rates for Unlevered Cash Flows and the Weighted Average Cost of Capital}

For finance practitioners, discounting expected unlevered cash flows at a tax-adjusted discount rate is the most popular way to value an asset. This section studies the relation between this discount rate and the after-tax weighted average cost of capital. It develops formulas for these discount rates for a variety of debt policies and shows when and why naive application of the weighted average cost of capital as the appropriate discount rate can generate erroneous valuations.

We take the perspective of an investor at date 0 . This investor would like to know the discount rate, applied to expected future unlevered cash flows, that generates $V_{0}^{L}$. Our analysis will show that this discount rate is rarely the $W A C C$ computed at date 0 . Before we do this, it is important to study the $W A C C$ and how it evolves through time.

\footnotetext{
${ }^{17}$ Simple algebraic manipulation indicates that the mapping from $D_{t}$ to $V_{L}$ associated with the equation below is given by

$$
V_{t}^{L}=V_{t}^{U}+\frac{r_{f}}{r_{f}-g_{0}^{d}} \tau_{c}\left(D_{t}+\frac{\left(1+r_{f}\right)\left(g-\eta-g_{0}^{d}\right)+\eta\left(r_{f}-g_{0}^{d}\right)}{\left(1+r_{f}\right)\left(r_{f}\left(1-\tau_{c} d^{v}\right)+\eta-g\right)-\eta r_{f} \tau_{c} d^{v}} d^{v} V_{t}^{U}\right) .
$$
}




\section{A. Risk, Expected Return, and the $W A C C$}

In continuous time, the weighted average cost of capital of an asset is defined to be the asset's instantaneous expected return, $r^{L}$, less the return component due to the debt tax shield:

$$
W A C C_{t}=r_{t}^{L}-r_{f} \tau_{c} \frac{D_{t}}{V_{t}^{L}}
$$

A levered asset's date $t$ instantaneous expected return, equivalent to its "pre-tax weighted average cost of capital," is defined by ${ }^{18}$

$$
r_{t}^{L} d t=\frac{\mathrm{E}_{t}\left(d V_{t}^{L}\right)+X_{t} d t+r_{f} \tau_{c} D_{t} d t}{V_{t}^{L}}
$$

This expected return has three components: the expected "capital gain," the unlevered cash flow, and the cash flow from the debt tax shield. ${ }^{19}$ One can readily show from the no arbitrage condition that

$$
r_{t}^{L}=r_{f}+\left(\frac{\partial \ln V_{t}^{L}}{\partial X_{t}}+\sigma_{H}\left(t, X_{t}, D_{t}, V_{t}^{L}\right) \frac{\partial \ln V_{t}^{L}}{\partial H_{t}}\right) \eta\left(t, X_{t}\right) X_{t}
$$

Combining this equation with equation (7) provides a direct formula for computing a $W A C C$ given the value of the levered asset:

$$
W A C C_{t}=r_{f}\left(1-\tau_{c} \frac{D_{t}}{V_{t}^{L}}\right)+\left(\frac{\partial \ln V_{t}^{L}}{\partial X_{t}}+\sigma_{H}\left(t, X_{t}, D_{t}, V_{t}^{L}\right) \frac{\partial \ln V_{t}^{L}}{\partial H_{t}}\right) \eta\left(t, X_{t}\right) X_{t} .
$$

Equation (9) is a generalization of the Modigliani-Miller adjusted cost of capital formula. It is convenient formula for computing the $W A C C$ given the extensive closed-form solutions computed in the last section. For example, in the case of constant debt for a finite-lived asset with zero expected growth and a constant risk premium for unlevered cash flows,

$$
\frac{\partial \ln V^{L}}{\partial H}=0
$$

and

$$
\frac{\partial \ln V_{t}^{L}}{\partial X_{t}}=\frac{V_{t}^{U}}{V_{t}^{L}} \frac{1}{X_{t}}
$$

In this case, the levered asset has a value of

$$
V_{t}^{L}=V_{t}^{U}+\tau_{c} D_{t}\left(1-e^{r_{f}(T-t)}\right)
$$

\footnotetext{
${ }^{18}$ This expected return is the appropriate discount rate for the "capital cash flow stream," which is the net payout to all cash flow claimants. See Ruback (2002) for a lucid discussion of the advantages of this approach.

${ }^{19}$ As mentioned earlier, the latter flow must be paid out to maintain the same investment policy and capital gains appreciation as an otherwise identical unlevered asset.
} 
the formula for the $W A C C$ reduces to

$$
W A C C_{t}=r^{U}\left(1-\tau_{c} \frac{D_{t}}{V_{t}^{L}}\right)-\left[\tau_{c} \eta \frac{D_{t}}{V_{t}^{L}}\left(1-e^{r_{f}(T-t)}\right)\right] .
$$

Note that the term in brackets is decreasing in $T$ and converges to zero for perpetual assets. Hence, this formula generates a smaller $W A C C$ than that generated by the Modigliani and Miller formula for perpetual assets.

It is also possible to write down a differential equation for the $W A C C$. Substituting the expected return formula, equation (8), into equation (7) implies

$$
W A C C_{t} d t=\frac{\mathrm{E}_{t}\left[d V_{t}^{L}\right]+X_{t} d t}{V_{t}^{L}} .
$$

Applying Ito's lemma to this equation, we find that the $W A C C$ satisfies the PDE

$W A C C \times V^{L}=\left(\frac{\partial V^{L}}{\partial t}+g X \frac{\partial V^{L}}{\partial X}+\frac{1}{2} \sigma^{2} X^{2} \frac{\partial^{2} V^{L}}{\partial X^{2}}+\mu^{h} \frac{\partial V^{L}}{\partial H}+\frac{1}{2} \sigma_{h}^{2} \frac{\partial^{2} V^{L}}{\partial H^{2}}+\sigma \sigma_{h} \frac{\partial^{2} V^{L}}{\partial H \partial X}\right) V^{L}+X$.

To understand the relation between the $W A C C$ and stochastic discount rates for unlevered cash flows, observe that $\rho_{t}$, the date $t$ stochastic instantaneous discount rate for $X_{t}$ that generates the value of the levered asset, satisfies the stochastic integral equation

$$
V_{t}^{L}=\int_{t}^{\infty} \mathrm{E}_{t}\left[e^{-\int_{t}^{s} \rho_{\omega} d \omega} X_{s}\right] d s
$$

By the Feynman-Kac theorem, any $\rho_{t}$ that satisfies this stochastic integral equation also satisfies the PDE

$\rho V^{L}=\left(\frac{\partial V^{L}}{\partial t}+g X \frac{\partial V^{L}}{\partial X}+\frac{1}{2} \sigma^{2} X^{2} \frac{\partial^{2} V^{L}}{\partial X^{2}}+\mu^{h} \frac{\partial V^{L}}{\partial H}+\frac{1}{2} \sigma_{h}^{2} \frac{\partial^{2} V^{L}}{\partial H^{2}}+\sigma \sigma_{h} \frac{\partial^{2} V^{L}}{\partial H \partial X}\right) V^{L}+X$.

Since the PDE that $\rho$ has to solve is identical to the PDE that the $W A C C$ solves (by Ito's lemma), the following proposition must hold: ${ }^{20}$

Proposition 1 The $W A C C$ is identical to the stochastic instantaneous discount rate that generates the levered asset value when applied to the unlevered cash flows.

This insight is not very useful for capital budgeting practitioners. As equation (9) indicates, the $W A C C$ at a future date depends on the state variables, $X$ and $H$, at that date. Hence, future $W A C C$ s are generally stochastic when viewed from date 0 , the relevant date of the valuation.

\footnotetext{
${ }^{20}$ Obviously, there is no reason for the boundary conditions to differ or for either of the partial differential equations to be ill-behaved.
} 


\section{B. The Appropriate Tax-Adjusted Discount Rates}

Even though the $W A C C$ is generally stochastic, it may be that some construct related to the $W A C C$ can be used to discount expected future unlevered cash flows to date 0 in a manner that accounts for the tax shield. This subsection explores this issue. We first begin by analyzing a discount rate, known at date 0 , that translates the expected unlevered cash flow at date $s$ into its value an instant earlier. We call this the "tax-adjusted forward rate." Once having developed an understanding what this tax-adjusted forward rate is, and how to compute it, we prove that the $W A C C$ is an appropriate tax-adjusted discount rate whenever the term structure of tax-adjusted forward rates is flat. These forward rates, while computable, are fairly impractical for capital budgeting purposes. However, they are consistent with a single tax-adjusted discount rate for unlevered cash flows - the taxadjusted hurdle rate for the $I R R$ - which generates the same present value. Moreover, when the unlevered assets are perpetual and the Gordon-Growth assumptions apply, this hurdle rate, denoted $\rho^{*}$, is easily obtained with a simple formula.

Define date 0's tax-adjusted forward discount rate for cash flows at date $s, f_{s}$, by

$$
f_{s} d s=\frac{\mathrm{E}_{0}\left[d V_{s}^{L}+X_{s} d s\right]}{\mathrm{E}_{0}\left[V_{s}^{L}\right]} .
$$

This is clearly an appropriate discount rate. It is known at date 0 , and the recursive relationship expressed in equation (11), applied iteratively, implies

$$
V_{0}^{L}=\int_{0}^{\infty} e^{-\int_{0}^{t} f_{s} d s} \mathrm{E}_{0}\left[X_{t}\right] d t .
$$

How does this series of forward rates relate to the $W A C C$ ? At most horizons, the comparison is meaningless because the future $W A C C \mathrm{~s}$ are stochastic when viewed from date 0 . As a general matter, the ratio of date 0 expectations in equation (11), used to compute the date $s$ forward rate, differs from the date 0 expectation of $W A C C_{s}$. Moreover, the expectations in equation (11), while obtainable, do not lend themselves to simple expressions.

Despite this, developing an understanding of tax-adjusted forward rates is useful for understanding when the $W A C C$ can be used for discounting. Trivially, $f_{s}$ converges to $W A C C_{0}$ as $s$ approaches zero. Because $f_{0}=W A C C_{0}$, and $f_{s}$ is an appropriate instantaneous discount rate for date $s$ cash flows, it follows that whenever $f_{s}=f_{0}$ for all $s, W A C C_{0}$ is an appropriate discount rate for unlevered cash flows.

Proposition 2 Whenever the term structure of tax-adjusted forward rates is flat $\left(f_{s}=\right.$ $\left.f_{0}, \forall s\right)$, the $W A C C$ is an appropriate tax-adjusted discount rate for unlevered cash flows.

Two cases where this situation arises are the no-growth Modigliani-Miller model and the Miles-Ezzell model (with or without cash flow growth). The only other situation where the 
forward term structure is flat is when debt policy is any weighted average of debt policies in these two models, but only for $g=g_{0}^{d}$. We explore this shortly.

The rarity of an equivalence between the initial $W A C C$ or expected future $W A C C$ s and the corresponding forward rates should not be surprising. Although equations (10) and (11) look similar, Jensen's inequality alone prevents the expectation of the former from equalling the latter when $V_{t}^{L}$, as well as the overall ratio in equation (10), are stochastic.

Date 0 's constant tax-adjusted discount rate, $\rho^{*}$, is defined by the equation

$$
V_{0}^{L}=\int_{0}^{\infty} e^{-\rho^{*} t} \mathrm{E}_{0}\left[X_{t}\right] d t
$$

In cases where the unlevered cash flows have perpetual constant growth $g$, this tax-adjusted discount (hurdle) rate is most easily computed as

$$
\rho^{*}=g+\frac{X_{0}}{V_{0}^{L}}
$$

Equation (13), an algebraic manipulation of the growing perpetuity formula, allows us to obtain $\rho^{*}$ from the formulas for $V_{0}^{L}$ developed in the prior section. ${ }^{21}$

\section{Classes of Cases with Easy Numerical Solutions}

Recall from the last section that the values of assets with time-independent cash flows and debt policy, as well as assets with additively separable history diffusion and debt equations could easily be obtained numerically. In the former class of cases, the fundamental valuation equation reduces to an ordinary differential equation in $X$. In the latter class, it reduces to a system of Riccati equations. In these cases, the $W A C C$ and appropriate discount rate, $\rho^{*}$ are similarly solved. Just as numerical solutions for $V^{L}$ are easily obtained, so too are the $W A C C$ using equation (9). For $\rho^{*}$, the formula in equation (13) generates the discount rate directly from the numerically solved $V^{L} .{ }^{22}$ Similarly, the forward rates are the solutions to ordinary differential equations which can be solved numerically. ${ }^{23}$

Obviously, it is more illuminating to analyze closed-form solutions for these interesting variables. We turn our attention to this next.

${ }^{21}$ With a finite-lived asset, $\rho *$ is easily identified implicitly as the parameter that solves

$$
V_{0}^{L}=\frac{X_{0}}{\rho^{*}-g}\left(1-e^{-\left(\rho^{*}-g\right)(T-t)}\right) .
$$

${ }^{22}$ For finite-lived assets, this discount rate can be easily solved implicitly, as described in the prior footnote.

${ }^{23}$ The ODEs are available upon request. 


\section{Additively Separable Assets with Closed-Form Solutions}

Consider, as in the last section, the case where history follows the diffusion

$$
d H_{t}=\left(m^{x}(t) X_{t}+m^{d} D_{t}+m^{v} V_{t}^{L}-m^{h} H_{t}\right) d t+\left(l^{x}(t) X_{t}+l^{d} D_{t}+l^{v} V_{t}^{L}-l^{h} H_{t}\right) d B_{t},
$$

and debt policy has the functional form

$$
D_{t}=\sum_{\lambda} d_{\lambda}^{x}(t) X_{t}^{\lambda}+d^{v} V_{t}^{L}+d^{h} H_{t}
$$

Recall that $g, \eta$, and $\sigma$ are constant, $d_{\lambda}^{x}(t)=d_{\lambda}^{x}(0) e^{g_{\lambda}^{d} t}, m_{\lambda}^{x}(t)-\eta l_{\lambda}^{x}(t)=k_{\lambda}^{x}(t)=k_{\lambda}^{x}(0) e^{g_{\lambda}^{k} t}$, and $T=\infty$. Here, the partial derivatives in equation (9) have closed-form solutions, allowing us to express the $W A C C$ as an explicit function of the unlevered cash flows, history state variable, and leverage ratio, $D_{t} / V_{t}$, as follows:

$$
W A C C_{t}=r_{f}\left(1-\tau_{c} \frac{D_{t}}{V_{t}^{L}}\right)+\frac{1 /\left(r_{f}+\eta-g\right)+\sum_{\lambda} c_{\lambda}^{x}(t) \lambda X_{t}^{\lambda-1}+c^{h}(t) \sigma_{H}}{V_{t}^{U}+\sum_{\lambda} c_{\lambda}^{x}(t) X_{t}^{\lambda}+c^{h}(t) H_{t}} \eta X_{t},
$$

where the $c$ coefficients are explicitly given in the prior section of the paper and with

$$
\sigma_{H}=\sum_{\lambda} l_{\lambda}^{x}(t) X_{t}+l^{d} D_{t}+l^{v} V_{t}^{L}-\left(l^{h}+\sigma\right) H_{t}
$$

\section{Case 1: Perpetual Assets}

Here, equation (14) simplifies to the same expression, but with

$$
c^{h}(t)=c_{\infty}^{h}
$$

and

$$
c_{\lambda}^{x}(t)=\frac{k_{\lambda}^{x}(t) c_{\infty}^{h}}{g_{\lambda}^{x}-g_{\lambda}^{k}}+\frac{\left(r_{f} \tau_{c}+k^{d} c_{\infty}^{h}\right) d_{\lambda}^{x}(t)}{g_{\lambda}^{x}-g_{\lambda}^{d}}+\frac{\left(k^{v}+k^{d} d^{v}\right) c_{\infty}^{h}+r_{f} \tau_{c} d^{v}}{\left(r^{U}-g\right)\left(r_{f}\left(1-\tau_{c} d^{v}\right)+\eta-g\right)} \delta_{\lambda, 1},
$$

and where the constants $g_{\lambda}^{x}$ and $c_{\infty}^{h}$ are given in the previous section of the paper. By contrast, the constant tax-adjusted discount rate is

$$
\rho^{*}=g+\frac{X_{0}}{\sum_{\lambda} c_{\lambda}^{x}(0) X_{0}^{\lambda}+c_{\infty}^{h} H_{0}} .
$$

\section{Case 2: Perpetual Debt as a Function of Cash Flows Only}

Consider, as in the last section, the case where

$$
D_{t}=\sum_{\lambda} d_{\lambda}^{x}(t) X_{t}^{\lambda}
$$


$g, \eta$, and $\sigma$ are constant, $d_{\lambda}^{x}(t)=d_{\lambda}^{x}(0) e^{g_{\lambda}^{d} t}$, and $T=\infty$. For this case, we showed that

$$
V_{t}^{L}=V_{t}^{U}+\sum_{\lambda} \frac{r_{f} \tau_{c}}{r_{f}+(\eta-g) \lambda-\frac{1}{2} \sigma^{2} \lambda(\lambda-1)-g_{\lambda}^{d}} d_{\lambda}^{x}(t) X_{t}^{\lambda} .
$$

This valuation solution simplifies equation (14) to

$$
W A C C_{t}=r_{f}\left(1-\tau_{c} \frac{D_{t}}{V_{t}^{L}}\right)+\frac{1 /\left(r_{f}+\eta-g\right)+\sum_{\lambda} c_{\lambda}^{x}(t) \lambda X_{t}^{\lambda-1}}{V_{t}^{U}+\sum_{\lambda} c_{\lambda}^{x}(t) X_{t}^{\lambda}} \eta X_{t},
$$

where

$$
c_{\lambda}^{x}(t)=\frac{r_{f} \tau_{c} d_{\lambda}^{x}(t)}{r_{f}+(\eta-g) \lambda-\frac{1}{2} \sigma^{2} \lambda(\lambda-1)-g_{\lambda}^{d}},
$$

while the constant tax-adjusted discount rate

$$
\rho^{*}=g+\frac{X_{0}}{V_{0}^{U}+\sum_{\lambda} \frac{r_{f} \tau_{c}}{r_{f}+(\eta-g) \lambda-\frac{1}{2} \sigma^{2} \lambda(\lambda-1)-g_{\lambda}^{d}} d_{\lambda}^{x}(0) X_{0}^{\lambda}} .
$$

This happens to be a case where the presentation of the term structure of tax-adjusted forward rates computed from the date 0 valuation date will not significantly lengthen the paper. To do this, we need to take date 0 expectations of $V_{s}^{L}$. Given the lognormal process for $X_{s}$, the formula for the conditional $\lambda^{\text {th }}$ moment of $X_{s}$ is

$$
\mathrm{E}_{0}\left[X_{s}^{\lambda}\right]=X_{0}^{\lambda} e^{\lambda\left(g-\frac{1}{2} \sigma^{2}\right) s+\frac{1}{2} \lambda^{2} \sigma^{2} s}
$$

which can be substituted into the expected value of equation (11). Thus,

$$
\mathrm{E}_{0}\left[V_{s}^{L}\right]=V_{0}^{U} e^{g s}+\sum_{\lambda} \tau_{c} r_{f} d_{\lambda}^{x} \frac{X_{0}^{\lambda} e^{\lambda\left(g-\frac{1}{2} \sigma^{2}\right) s+\frac{1}{2} \lambda^{2} \sigma^{2} s}}{r_{f}+(\eta-g) \lambda-\frac{1}{2} \sigma^{2} \lambda(\lambda-1)} .
$$

It follows that

$$
\frac{d \mathrm{E}_{0}\left[V_{s}^{L}\right]}{d s}=V_{0}^{U} g e^{g s}+\sum_{\lambda} \tau_{c} r_{f} d_{\lambda}^{x} \frac{\left(\lambda\left(g-\frac{1}{2} \sigma^{2}\right)+\frac{1}{2} \lambda^{2} \sigma^{2}\right) X_{0}^{\lambda} e^{\lambda\left(g-\frac{1}{2} \sigma^{2}\right) s+\frac{1}{2} \lambda^{2} \sigma^{2} s}}{r_{f}+(\eta-g) \lambda-\frac{1}{2} \sigma^{2} \lambda(\lambda-1)} .
$$

We now have all the ingredients to compute the date $s$ tax-adjusted forward rate. It is given by the formula:

$$
f_{s}=\frac{V_{0}^{U}\left(r_{f}+\eta\right) e^{g s}+\sum_{\lambda} \tau_{c} r_{f} d_{\lambda}^{x} \frac{\left(\lambda\left(g-\frac{1}{2} \sigma^{2}\right)+\frac{1}{2} \lambda^{2} \sigma^{2}\right) X_{0}^{\lambda} e^{\lambda\left(g-\frac{1}{2} \sigma^{2}\right) s+\frac{1}{2} \lambda^{2} \sigma^{2} s}}{r_{f}+(\eta-g) \lambda-\frac{1}{2} \sigma^{2} \lambda(\lambda-1)}}{V_{0}^{U} e^{g s}+\sum_{\lambda} \tau_{c} r_{f} d_{\lambda}^{x} \frac{X_{0}^{\lambda} e^{\lambda\left(g-\frac{1}{2} \sigma^{2}\right) s+\frac{1}{2} \lambda^{2} \sigma^{2} s}}{r_{f}+(\eta-g) \lambda-\frac{1}{2} \sigma^{2} \lambda(\lambda-1)}}
$$

It is easily verified that $W A C C_{0}=f_{0}$, but obviously, the date $s W A C C$ depends on $X_{s}$ and thus cannot be identical to $f_{s}$. Moreover, the date $s$ forward rate is not the date 0 
expectation of the date $s W A C C$, irrespective of whether expectations are taken with respect to the actual probability density function or the probability density function generated by the risk-neutral measure.

\section{Case 3: Perpetual Debt that is a Linear Function of Asset Value Plus Constant Growth}

Recall that for this special case, explored in the last section, debt policy is given by

$$
D_{t}=d_{0}^{x}(0) e^{g_{0}^{d} t}+d^{v} V_{t}^{L}
$$

and a perpetual levered asset has a particularly simple functional form for its valuation:

$$
V_{t}^{L}=V_{t}^{U}+\tau_{c}\left(\frac{r_{f}}{r_{f}\left(1-\tau_{c} d^{v}\right)-g_{0}^{d}} d_{0}^{x}(t)+\frac{r_{f}}{r_{f}\left(1-\tau_{c} d^{v}\right)+\eta-g} d^{v} V_{t}^{U}\right) .
$$

This valuation solution simplifies equation (14) to

$$
W A C C_{t}=r_{f}\left(1-\tau_{c} \frac{D_{t}}{V_{t}^{L}}\right)+\frac{\eta X_{t}}{\left(r_{f}\left(1-\tau_{c} d^{v}\right)+\eta-g\right) V_{t}^{L}},
$$

with $V_{t}^{L}$ given by the equation immediately above, while the appropriate tax-adjusted constant discount rate, $\rho^{*}$, is given by

$$
\rho^{*}=g+\frac{X_{0}}{V_{0}^{U}+\tau_{c}\left(\frac{r_{f}}{r_{f}\left(1-\tau_{c} d^{v}\right)-g_{0}^{d}} d_{0}^{x}(t)+\frac{r_{f}}{r_{f}\left(1-\tau_{c} d^{v}\right)+\eta-g} d^{v} V_{0}^{U}\right)} .
$$

Using equation (11), the simple valuation formula for this case can be used to show that the tax-adjusted forward discount rate is given by the weighted average

$$
f_{s}=\frac{\gamma_{0}(s)}{\gamma_{0}(s)+\gamma_{1}(s)} g_{0}^{d}+\frac{\gamma_{1}(s)}{\gamma_{0}(s)+\gamma_{1}(s)}\left(r_{f}\left(1-\tau_{c} d^{v}\right)+\eta\right)
$$

where the coefficients

$$
\begin{aligned}
\gamma_{0}(s) & =\frac{r_{f} \tau_{c} d_{0}^{x}(0)}{r_{f}\left(1-\tau_{c} d^{v}\right)-g_{0}^{d}} e^{g_{0}^{d} s}, \\
\gamma_{1}(s) & =\frac{X_{0}}{r_{f}\left(1-\tau_{c} d^{v}\right)+\eta-g} e^{g s},
\end{aligned}
$$

and

$$
V_{0}^{L}=\gamma_{0}(0)+\gamma_{1}(0)
$$

It is possible to compare forward rates, $W A C C \mathrm{~s}$, and appropriate constant tax-adjusted discount rates here but the discussion is more illuminating if we focus on several special cases of this example. 
Case 3a: Constantly Growing Debt with No Stochastic Component and No Expected Cash Flow Growth

In this extension of the Modigliani-Miller debt policy that accounts for the possibility of growing debt, $g=d^{v}=0$, and $r_{f}>g_{0}^{d}>0$. The $\gamma_{0}(s)$ and $\gamma_{1}(s)$ coefficients above simplify to

$$
\begin{aligned}
& \gamma_{0}(s)=\frac{r_{f} \tau_{c} D_{0}}{r_{f}-g_{0}^{d}} e^{g_{0}^{d} s}=\Delta_{0} e^{g_{0}^{d} s}, \\
& \gamma_{1}(s)=\frac{X_{0}}{r_{f}+\eta}=V_{0}^{U},
\end{aligned}
$$

implying

$$
f_{s}=\frac{\Delta_{0} e^{g_{0}^{d} s} g_{0}^{d}}{V_{0}^{U}+\Delta_{0} e^{g_{0}^{d} s}}+\frac{V_{0}^{U}}{V_{0}^{U}+\Delta_{0} e^{g_{0}^{d} s}} r^{U} .
$$

The initial $W A C C$, which is identical to $f_{0}$, is

$$
\begin{aligned}
W A C C_{0} & =\frac{\Delta_{0}}{V_{0}^{L}} g_{0}^{d}+\frac{V_{0}^{U}}{V_{0}^{L}} r^{U} \\
& =r^{U}\left(1-\tau_{c} \frac{D_{0}}{V_{0}^{L}}\right)-\frac{\eta}{r_{f}-g_{0}^{d}} g_{0}^{d} \tau_{c} \frac{D_{0}}{V_{0}^{L}}
\end{aligned}
$$

However, the tax-adjusted constant discount rate is

$$
\rho^{*}=\frac{X_{0}}{V_{0}^{L}}=r^{U} \frac{V_{0}^{U}}{V_{0}^{L}}=r^{U}\left(1-\frac{r_{f}}{r_{f}-g_{0}^{d}} \tau_{c} \frac{D_{0}}{V_{0}^{L}}\right),
$$

which the initial $W A C C$ exceeds by the amount

$$
\frac{\Delta_{0}}{V_{0}^{L}} g_{0}^{d}=\frac{r_{f}}{r_{f}-g_{0}^{d}} g_{0}^{d} \tau_{c} \frac{D_{0}}{V_{0}^{L}} .
$$

Case 3b: Modigliani-Miller Static Debt Policy with Constant Expected Growth in Cash Flows

Here we assume that $g>0$, but that $d^{v}=g_{0}^{d}=0$. In this case

$$
\begin{aligned}
\gamma_{0}(s) & =\tau_{c} D_{0} \\
\gamma_{1}(s) & =\frac{X_{0}}{r_{f}+\eta-g} e^{g s}=V_{0}^{U} e^{g s},
\end{aligned}
$$

implying

$$
f_{s}=\frac{V_{0}^{U}}{V_{0}^{L}} e^{g s} r^{U} .
$$


The initial $W A C C$, which is identical to $f_{0}$, is

$$
W A C C_{0}=\frac{V_{0}^{U}}{V_{0}^{L}} r^{U}=r^{U}\left(1-\tau_{c} \frac{D_{0}}{V_{0}^{L}}\right) .
$$

However, the tax-adjusted constant discount rate is

$$
\begin{aligned}
\rho^{*} & =\frac{X_{0}}{V_{0}^{L}}+g=\frac{V_{0}^{U}}{V_{0}^{L}}\left(r^{U}-g\right)+g \\
& =\frac{V_{0}^{U}}{V_{0}^{L}} r^{U}+g \tau_{c} \frac{D_{0}}{V_{0}^{L}}
\end{aligned}
$$

which exceeds the initial $W A C C$ by $g \tau_{c} \frac{\mathrm{D}_{0}}{V_{0}^{L}}$.

\section{Case 3c: The Modigliani-Miller Model with Equal Growth in Debt and Expected Cash Flows}

The last two cases illustrated that the $W A C C$ was not an appropriate tax-adjusted constant

discount rate. This is because it changed over time. In Case $3 a$, the initial $W A C C$ was too large because it was expected to decrease. In Case $3 \mathrm{~b}$, the initial $W A C C$ was too small because it was expected to increase. It is natural to think that if $d^{v}=0$ but $g_{0}^{d}=g>0$, so that debt growth keeps pace with the expected growth of the cash flows, the initial $W A C C$ will still work. This indeed is the case. To prove this, note that here

$$
W A C C_{0}=f_{0}=\frac{\Delta_{0}}{V_{0}^{L}} g_{0}^{d}+\frac{V_{0}^{U}}{V_{0}^{L}} r^{U}=r^{U}\left(1-\tau_{c} \frac{D_{0}}{V_{0}^{L}}\right)-\frac{\eta}{r_{f}-g_{0}^{d}} g_{0}^{d} \tau_{c} \frac{D_{0}}{V_{0}^{L}}
$$

Thus, $W A C C_{0}=\rho^{*}$ whenever

$$
\frac{\Delta_{0}}{V_{0}^{L}} g_{0}^{d}+\frac{V_{0}^{U}}{V_{0}^{L}} r^{U}=g+\frac{\left(r^{U}-g\right) V_{0}^{U}}{V_{0}^{L}},
$$

which only occurs when $g_{0}^{d}=g$.

This happens to be a case in which the forward rate is independent of $s$. By Proposition 2 , the initial $W A C C$ has to work as an appropriate tax-adjusted discount rate under this condition.

\section{Case 3d: A Combination of the Extended Modigliani-Miller and Miles-Ezzell Debt Models with Equal Growth in Debt and Expected Cash Flow}

Here, we generalize Case $3 \mathrm{c}$ and once again show that the initial $W A C C$ is an appropriate discount rate for unlevered cash flows. In this example, $g_{0}^{d}=g$ but $d^{v}$ may be nonzero. These assumptions imply:

$$
\begin{aligned}
& \frac{\gamma_{0}(s)}{\gamma_{0}(s)+\gamma_{1}(s)}=1-\frac{X_{0}}{V_{0}^{L}} \times \frac{1}{r_{f}\left(1-\tau_{c} d^{v}\right)+\eta-g} \\
& \frac{\gamma_{1}(s)}{\gamma_{0}(s)+\gamma_{1}(s)}=\frac{X_{0}}{V_{0}^{L}} \times \frac{1}{r_{f}\left(1-\tau_{c} d^{v}\right)+\eta-g} .
\end{aligned}
$$


To compute $f_{s}$, the former ratio multiplies $g$, while the latter multiplies $r_{f}\left(1-\tau_{c} d^{v}\right)+\eta$, and then the two products are summed. Thus,

$$
f_{s}=f=\rho^{*}=W A C C_{0}=g+\frac{X_{0}}{V_{0}^{L}} .
$$

When $g_{0}^{d} \neq g, f_{s}$ depends on s. Hence, within Case 3 , it is only by imposing the condition $g_{0}^{d}=g$ that one can use the initial $W A C C$ as an appropriate discount rate. This discount rate can be thought of as a weighted average of the $W A C C$ from a Miles and Ezzell debt policy at an initial debt of $D_{0}$ and the $W A C C$ from a Modigliani and Miller debt policy at an initial debt of $D_{0}$. Specifically, denote the $W A C C$ s of Modigliani-Miller and Miles-Ezzell as

$$
\begin{gathered}
W A C C_{0}^{M M}=r^{U}\left(1-\tau_{c} \frac{D_{0}}{V_{0}^{L}}\right)-\frac{g \eta}{r_{f}-g} \tau_{c} \frac{D_{0}}{V_{0}^{L}} \\
W A C C_{0}^{M E}=r^{U}-\tau_{c} r_{f} \frac{D_{0}}{V_{0}^{L}},
\end{gathered}
$$

respectively. Then the discount rate given above

$$
W A C C_{0}=\rho^{*}=f=w_{0} W A C C_{0}^{M M}+\left(1-w_{0}\right) W A C C_{0}^{M E},
$$

where

$$
w_{0}=\frac{r_{f}-g}{r_{f}\left(1-\tau_{c} d^{v}\right)-g}\left(1-\frac{d^{v}}{D_{0} / V_{0}^{L}}\right) .
$$

\section{Case 3e: The Growth Extension of the Miles-Ezzell model}

Consider the case with $d^{v}=D_{0} / V_{0}, d_{0}^{x}(0)=0$. This is a continuous-time version of the Miles-Ezzell model, but with the extension of expected growth in cash flows. Here,

$$
V_{t}^{U}=\frac{X_{t}}{r_{f}+\eta-g}
$$

and

$$
V_{t}^{L}=V_{t}^{U}+\frac{r_{f}}{r_{f}+\eta-g} \tau_{c} D_{t}
$$

In this case, since $\gamma_{0}(s)$ is zero, the date $s$ forward rate is independent of $s$, which has the value

$$
f=\rho^{*}=r^{U}-r_{f} \tau_{c} \frac{D_{0}}{V_{0}^{L}}
$$

This tax-adjusted discount rate is identical to the weighted average cost of capital. 
To understand this from another perspective, recognize that everything is stationary here, and that the flow from the debt tax shield, being proportional to the unlevered cash flow, shares its discount rate, so that

$$
r^{L}=r_{f}+\eta .
$$

The $W A C C$, from equation (7), is therefore the constant

$$
W A C C_{t}=r_{f}+\eta-r_{f} \tau_{c} \frac{D}{V^{L}}
$$

where, by assumption, $D / V^{L}$ is the same at all points in time. Note that the growth rate of the cash flows never appears when the $W A C C$ is written as a function of the leverage ratio, but that it affects $V^{L}$ above.

\section{E. Discussion}

To develop an intuitive understanding of the results above it is useful to first review why discounting unlevered cash flows at the initial after-tax weighted average cost of capital sometimes accounts for the value of the debt tax shield. Let's begin with the perpetual level debt model of Modigliani and Miller. Because the market value of the debt financing never changes in this model, it is useful to think of the Modigliani and Miller analysis as the valuation of the debt tax shield of a zero beta debt strategy. In such a model, the familiar equation $V^{L}=V^{U}+\tau_{c} D$ reflects the separate valuations of the two components of the asset: the unlevered after-tax cash flow stream, with stochastic value $X_{t}$ at date $t$, and the stream of cash flows from the interest-based tax shield, $D r_{f} \tau_{c}$, which is constant and identical at every date. Note that the gross (as opposed to net) pre-tax weighted average cost of capital, which is also the gross expected return on the levered asset, is

$$
1+r^{L}=1+\left(D / V^{L}\right) r_{f}+\left(E / V^{L}\right) r_{E} .
$$

This can be viewed as the expected cash flow per dollar of assets to investors who buy an asset, hold it for an instant, and then liquidate it. Both the asset value and the flow include the debt tax shield. Hence, the gross after-tax $W A C C$

$$
1+\left(D / V^{L}\right) r_{f}\left(1-\tau_{c}\right)+\left(E / V^{L}\right) r_{E}
$$

is just the expected flow to investors per dollar of levered assets, less the expected flow per dollar of assets from the debt tax shield, $\left(D / V^{L}\right) r_{f} \tau_{c}$. This net flow is identical to the unlevered cash flow per dollar of levered assets. Viewed with the arrow of time in reverse, this insight implies that if we discount the unlevered cash flows at the after-tax $W A C C$, we end up back where we started, with the one dollar value of the assets, including that component of value generated by the debt tax shield. 
It is easy to see that this insight about the zero beta debt strategy does not easily extend to the case of an asset with a value that tends to grow. Here, the value of the unlevered asset is affected by the growth rate, but the debt tax shield, having a perpetual value of $\tau_{c} D$ is not affected by it. Because the value of such a constant debt tax shield tends to decline over time as a proportion of total asset value, the initial after-tax weighted average cost of capital is an inappropriate discount rate for all future cash flows. Essentially, the weighted average cost of capital is changing over time. In this simple case, we learned that there is a single discount rate that can be used to discount all future unlevered cash flows: the sum of the initial after-tax $W A C C$ and $g \tau_{c} D / V^{L}$, the latter being the product of the growth rate of the unlevered cash flows, the tax rate, and the debt to value ratio. For a firm with a $4 \%$ growth rate, and a 50\% tax rate and leverage, this alone represents a 100 basis point error in the discount rate, even given the true unlevered cost of capital. We can see that if the risk of the levered asset is not expected to change, as in the Modigliani-Miller model of debt adjustment, which assumes no growth, discounting the expected unlevered cash flow stream at the initial $W A C C$ generates the value of the levered assets, including the debt tax shield.

The other case where the risk of the levered asset is not expected to change arises in an extension of the Miles and Ezzell (1985) model. Their case is one where the debt level is adjusted over time to maintain a constant debt to value ratio. This is a positive beta debt strategy even though the debt, at issue, is risk-free. The perpetually constant $W A C C$ is an appropriate discount rate in this case, but the valuation is never out of peril if the actual debt policy associated with the asset differs from the policy implicit in the formulas used for the valuation. For example, if the unlevered asset's risk premium is twice the risk-free rate, the Miles-Ezzell tax shield is a mere one-third that of the Modigliani-Miller debt tax shield for the same debt level. If the risk-free rate is $4 \%$, the bias in the $W A C C$ from applying a Miles-Ezzell formula to Modigliani-Miller debt policy becomes 200 basis points, even if the unlevered cost of capital for the asset is estimated perfectly.

These problems can become much more severe when the unlevered cost of capital is from comparison assets with debt policies that are also mismatched to the formulas. For example, an asset with a nonstochastic trend to grow its debt but pay it down if the cash flows turn out to be surprisingly good, has a very low $W A C C$ other things equal. Unless this is recognized, unlevering such an asset with a standard formula tends to produce too low an unlevered cost of capital. Similarly, obtaining the $W A C C$ of such an asset at a target debt level using the standard formulas tends to produce too large a $W A C C$. By contrast, consider an asset for which debt has a nonstochastic retirement trend, but for which debt tends to increase rapidly when cash flows are surprisingly good. Applying the standard formulas to such an asset tends to generate unlevered costs of capital that are too high given a known $W A C C$ and a $W A C C$ at a target debt level that is too low given the asset's unlevered cost of capital. If the former asset has a known $W A C C$ and is used to generate the $W A C C$ for the latter 
asset, (or vice versa), the bias can easily run to 500 basis points or more. ${ }^{24}$

\section{Levering and Unlevering Equity Betas}

The relationship between equity betas and unlevered asset betas is critical for valuation. Equity betas, unlike asset betas, are observed. Hence, to obtain the necessary discount rates, valuations analyze the traded equity of assets that are deemed similar to the asset being valued. The problem is that the risk of the traded equity of comparison assets is affected by the leverage policy associated with the comparison asset. It is generally necessary to undo the leverage-induced distortion on the equity beta of the comparison asset(s) in order to obtain the critical valuation inputs: the unlevered asset beta or unlevered cost of capital. This section explores how to do this.

The return on an unlevered asset is given by

$$
\frac{d V^{U}+X_{t} d t}{V^{U}}=\left(r_{f}+\eta \frac{\partial \ln V^{U}}{\partial \ln X}\right) d t+\frac{\partial \ln V^{U}}{\partial \ln X} \sigma d B
$$

while the return on a levered asset is given by

$\frac{d V^{L}+X d t+r_{f} \tau_{c} D d t}{V^{L}}=\left(r_{f}+\left(\frac{\partial \ln V^{L}}{\partial X}+\sigma_{H} \frac{\partial \ln V^{L}}{\partial H}\right) \eta X\right) d t+\left(\frac{\partial \ln V^{L}}{\partial X}+\sigma_{H} \frac{\partial \ln V^{L}}{\partial H}\right) \sigma X d B$

The ratio of the terms that multiply $d B$ in the two equations above represent the effect of leverage on volatility. With risk-free debt, the proportional effect on beta is the same. Moreover, with risk-free debt, the equity beta of a levered asset always is $1+D / E$ times the beta of the underlying asset (including the asset component from the tax shield. ${ }^{25}$ It follows that the formula for levering and unlevering equity betas involves multiplying $1+D / E$ by the ratio of the terms that multiply $d B$ above. That is,

$$
\beta_{t}^{E}=\left(1+\frac{D_{t}}{E_{t}^{L}}\right) \frac{\frac{\partial \ln V^{L}}{\partial X}+\sigma_{H} \frac{\partial \ln V^{L}}{\partial H}}{\frac{\partial \ln V^{U}}{\partial X}} \beta_{t}^{U}
$$

with the derivatives taken at date $t$.

The above equation suggests that whenever there is a closed-form solution for the levered asset value, there is a closed-form solution for the equity beta formula, obtainable after first taking partial derivatives. For example, the extension of the Modigliani-Miller debt policy with $g \neq 0$ and $g_{0}^{d} \neq 0$ has

$$
\frac{\partial \ln V^{L}}{\partial H}=0
$$

\footnotetext{
${ }^{24}$ Moreover, this analysis assumes that the WACC is an appropriate discount rate, which it rarely is.

${ }^{25}$ This is just an inversion of the portfolio formula that generates the beta of the levered asset as a portfolio-weighted average of the beta of its debt (zero) and equity $\left(\beta^{E}\right)$.
} 
and

$$
\frac{\partial \ln V^{L}}{\partial X}=\frac{V^{U}}{V^{L}} \frac{\partial \ln V^{U}}{\partial X}
$$

which implies

$$
\beta_{t}^{E}=\left[1+\left(1-\tau_{c} \frac{r_{f}}{r_{f}-g_{0}^{d}}\right) \frac{D_{t}}{E_{t}^{L}}\right] \beta_{t}^{U} .
$$

When $g_{0}^{d}$ is nonzero, this formula differs from the leveraging-unleveraging formula proposed by Hamada (1972) for the Modigliani and Miller debt policy. It also differs from this formula when $g=g_{0}^{d}=0$ but the asset has a finite life. In the latter case,

$$
\frac{\partial \ln V^{L}}{\partial H}=0
$$

and

$$
\frac{\partial \ln V^{L}}{\partial X}=\frac{V^{U}}{V^{L}} \frac{\partial \ln V^{U}}{\partial X}
$$

However, because the finite horizon debt tax shield has a different value than the perpetual debt tax shield, the formula reduces to

$$
\beta_{t}^{E}=\left[1+\left(1-\tau_{c}\left(1-e^{-r_{f}(T-t)}\right)\right) \frac{D_{t}}{E_{t}^{L}}\right] \beta_{t}^{U} .
$$

By contrast, the extension of the Miles-Ezzell policy with $g \neq 0$ has

$$
\frac{\partial \ln V^{L}}{\partial H}=0
$$

and

$$
\frac{\partial \ln V^{L}}{\partial X}=\frac{\partial \ln V^{U}}{\partial X}=1 / X
$$

implying

$$
\beta_{t}^{E}=\left(1+\frac{D_{t}}{E_{t}^{L}}\right) \beta_{t}^{U}
$$

This is identical to the formula proposed by Miles and Ezzell and it applies to both an infinitely-lived and finite-lived asset (in contrast to the Hamada formula for the ModiglianiMiller debt policy).

For a perpetual asset that is a hybrid of the Modigliani-Miller and Miles-Ezzell debt policies, as given in Case 3 of the prior sections of the paper, the equity beta formula is

$$
\beta_{t}^{E}=\left[1+\left(1+\tau_{c}\left(\frac{d^{v}}{D_{t} / E_{t}}-1\right) \frac{r_{f}}{r_{f}\left(1-\tau_{c} d^{v}\right)-g_{0}^{d}}\right) \frac{D_{t}}{E_{t}}\right] \beta_{t}^{U} .
$$


The formula above is a weighted average of the beta leveraging formulas of Hamada/ModiglianiMiller and Miles-Ezzell. That is

$$
\beta_{t}^{E}=\left[w_{t}\left(1+\left(1-\tau_{c} \frac{r_{f}}{r_{f}-g_{0}^{d}}\right) \frac{D_{t}}{E_{t}^{L}}\right)+\left(1-w_{t}\right)\left(1+\frac{D_{t}}{E_{t}}\right)\right] \beta_{t}^{U}
$$

with the weight on Hamada/Modigliani-Miller formula

$$
w_{t}=\frac{r_{f}-g_{0}^{d}}{r_{f}\left(1-\tau_{c} d^{v}\right)-g_{0}^{d}}\left(1-\frac{d^{v}}{D_{t} / V_{t}^{L}}\right) .
$$

There are several additional cases with simple closed-form solutions for the equity beta. These parallel cases 1 and 2 in the prior two sections of the paper. Since these involve mere substitutions and elementary calculus, we omit them for the sake of brevity.

Finally, we note that since equity risk premia are proportional to equity betas, the formulas for leveraging and unleveraging equity risk premia are the same as those above, with the levered and unlevered equity risk premia substituting for their respective betas above.

\section{Conclusion}

This paper has undertaken a comprehensive valuation of debt tax shields. In as many cases as possible, we offered closed-form solutions for the values of levered assets and the associated debt tax shields. Our approach for obtaining these present values was the APV approach. The tax-adjusted discount rates that generate the present values were reverse engineered, in that we needed to use the present values to generate closed-form solutions for the discount rates. In this sense, we are in the APV camp, rather than the WACC camp, and like many academics fail to understand why the APV approach is not viewed as the simpler technique. Obviously, however, both approaches are equivalent and it is possible to generate correct valuations either way once the debt policy and cash flow process are known.

The examples explored in this paper are particularly useful in that most dynamic debt policies can be thought of as fitting into one of these examples. The examples demonstrated that it is possible to develop intuition from polar cases so that a manager can heuristically assess how his discount rate and debt tax shield value will change, given the dynamic nature of the policy. For instance, firms with debt policies that sluggishly but positively react to changes in the value of the firm's unlevered assets might be expected to have a debt tax shield with a value that lies somewhere between the Modigliani-Miller and Miles-Ezzell values. The appropriate tax-adjusted constant discount rate for the future cash flows of the unlevered assets, as well as the formulas for levering and unlevering equity betas will also lie between the values given by the polar cases. Moreover, when firms engage in what we term "negative beta debt policies," paying down debt as the cash flow prospects brighten, 
and vice versa, the formulas for the debt tax shield, discount rate, and levered equity betas are again weighted averages of the two polar cases, with a negative weight on the formula associated with the Miles-Ezzell positive-beta debt strategy and a weight above one on the Modigliani-Miller zero-beta debt strategy formula.

The comprehensive treatment of debt tax shields presented here is essential for practitioners. Confusion has proliferated because the formulas that previously had been developed for the simplest of cases are generally treated as black boxes without a clear understanding of where they come from. It is rare when pedagogy appropriately links the formulas for levering and unlevering betas to the value of the tax shield. The Miles-Ezzell valuation can easily be $1 / 3$ the valuation using the Modigliani-Miller approach. It is quite common, however, to observe both students and finance professors mix the Miles and Ezzell formula for leveraging and unleveraging equity with Modigliani-Miller inputs, thinking that they are getting a valuation of $\tau_{c} D$ for the debt tax shield. In properly linking the values of tax shields for different debt policies to discount rates and laying out the theory behind this linkage, we hope to remedy some of this confusion.

This paper is important, however, not just for those doing corporate valuations, but for those doing research on capital structure and bankruptcy costs. In particular, it provides a comprehensive set of benchmarks for the impact of debt on asset values in a market that is frictionless, except for taxes. Empirical research by Graham (2000) and by Kemsley and Nissim (2001) indicates that for the average U.S. firm, debt tax shields in the U.S. are about the size of $\tau_{c} D$. Clearly, more research that describes the cross-sectional variation in this estimate is coming, and is warranted. To properly estimate bankruptcy costs from extensions of this research, it is critical to know the value of the debt tax shield in a market where the only friction is taxes. We believe that research in this area has been hindered by a lack of understanding of benchmark valuations. In plugging this hole in the literature, we hope to stimulate additional research. 


\section{References}

[1] Brealey, Richard and Stewart Meyers (2000), Principles of Corporate Finance, McGraw-Hill/Irwin.

[2] Graham, John (2000), "How Big Are the Tax Benefits of Debt?" Journal of Finance, Vol. 55, No. 5, pp. 1901-1942.

[3] Graham, John, and Campbell Harvey (2000), "The Theory and Practice of Corporate Finance: Evidence from the Field," Journal of Financial Economics, Vol. 60, No. 2-3, pp. 187-243.

[4] Green, Richard C., and Burton Hollifield (2002), "The Personal-Tax Advantages of Equity," Journal of Financial Economics, forthcoming, Vol. 67, No. 2.

[5] Grinblatt, Mark and Sheridan Titman (2002, 2nd ed.; 1997, 1st ed.), Financial Markets 83 Corporate Strategy, McGraw-Hill/Irwin.

[6] Hamada, Robert (1972), "The Effect of the Firm's Capital Structure on the Systematic Risk of Common Stocks," Journal of Finance, Vol. 27, No. 2, pp. 435-452.

[7] Kemsley, Deen and Doron Nissim (2002), "Valuation of the Debt-Tax Shield," forthcoming, Journal of Finance.

[8] Leland, Hayne (1994), "Corporate Debt Value, Bond Covenants, and Optimal Capital Structure," Journal of Finance, Vol. 49, No. 4, pp. 1213-1252.

[9] Miles, James and Russell Ezzell (1985), "Reformulating Tax Shield Valuation," Journal of Finance, Vol. 40, No. 5 , pp. 1485-1492.

[10] Modigliani, Franco and Merton Miller (1958), "The Cost of Capital, Corporation Finance and the Theory of Investment," The American Economic Review, Vol. 48, No. 3, pp. 261-297.

[11] Ross, Stephen (1978), "A Simple Approach to the Valuation of Risky Streams," Journal of Business, Vol. 51, No. 3, pp. 453-475.

[12] Ruback, Richard (2002), "Capital Cash Flows: A Simple Approach to Valuing Risky Cash Flows," Financial Management, Vol. 31, No. 2, pp.85-103. 